\section{The cause(s) of neural tube defect}

SIR,

Professor Fraser and colleagues ${ }^{1}$ cite evidence relating to my hypothesis ${ }^{2} 3$ proposing two separate causes for anencephaly. However, the difficulty they adduce is one I have already treated. ${ }^{4}$ In that note I discussed the possibility that the two hypothesised causes act synergistically. It remains to be seen whether this is a useful suggestion.

Another point they raise is the tendency for sibships to remain 'true' to one or other of the two malformations. There are other grounds for supposing that anencephaly and spina bifida do not have identical causes, or that, if they are identical, they are not applied at the same time in gestation. ${ }^{5}$

W H JAMES MRC Mammalian Development Unit, Wolfson House, 4 Stephenson Way, London NW1 $2 H E$.

\section{References}

${ }^{1}$ Fraser FC, Maldoff SR, Lippman-Hand A. Evidence against a female specific class of neural tube defect. $J$ Med Genet $1983 ; 20: 78-9$.

2 James WH. The sex ratio in spina bifida. $J$ Med Genet 1979;16:384-8.

3 James WH. The sex ratio in anencephaly. $J$ Med Genet 1979;16:129-33.

4 James WH. The sex ratios of anencephalics born to anencephalic-prone women. Dev Med Child Neurol 1980; 22:618-22.

5 James WH. Differences between the events preceding spina bifida and anencephaly. J Med Genet 1981;18: 17-21.

\section{Absence of the fragile $X$ in a group of patients with idiopathic mental retardation}

SIR,

The apparently high incidence of the fragile $X$ syndrome ${ }^{1}$ has led to the recommendation that all males with 'idiopathic' or 'non-specific' mental retardation should be screened for this condition. Such studies can have a significant impact on the load of a cytogenetic laboratory. We studied 17 of the 20 male patients from our group of 36 children with 'idiopathic' retardation who also lacked any major malformations, as defined in our study of 406 institutionalised children in Manitoba. ${ }^{2}$ Heparinised blood samples were cultured in medium TC 199 enriched with $5 \%$ fetal calf serum according to the protocol of Sutherland. ${ }^{3}$ One hundred solid stained metaphases were examined for long arm breaks in the $\mathrm{C}$ group chromosomes. These were then photo- $\overrightarrow{\vec{F}}$ graphed and the slides destained and Giemsa? banded for positive identification of the $\mathrm{C}$ group? chromosomes.

None of the 17 patients showed a fragile $X$. We do $\frac{\bar{p}}{\widehat{\sigma}}$ not believe known methodological variables caused $\stackrel{\varnothing}{\circ}$ these negative results, ${ }^{4}$ since several positive families were processed in the laboratory at the time.

As demand increases on cytogenetic laboratories, it is essential to look for better ways to select $\vec{\omega}$ patients for study and we have therefore looked? more closely at the clinical features of our group First, by our definition, ${ }^{2}$ they all lacked a positivei family history and thus, if fragile $X$ positive, would have to represent a relatively recent mutational $\omega$ event. While the full spectrum of the fragile $X \vec{P}$ syndrome is yet to be established, patients with a proven fragile $\mathrm{X}$ chromosome tend to have normal 은 body proportions, including occipitofrontal circum- $\rightarrow$ ference (OFC), and lack associated neurological signs. Many have large jaws, prominent ears, and/ore macro-orchidism..$^{5}$ By contrast, seven of our $17^{\stackrel{\rho}{+}}$ patients had a head circumference less than the $3 \mathrm{rd} \overrightarrow{\ddot{O}}$ centile and two were less than the 3rd centile in height. Marked abnormalities of muscle tone were the rule and were occasionally accompanied by overt neurological signs such as nystagmus or cortical blindness. Minor anomalies of the face and hands were frequent. None of the seven postpubertal males $\stackrel{\circ}{\mathcal{D}}$ had macro-orchidism and one was noted to have $\varrho$ small testes. Similarly, Renpenning's original family $\overrightarrow{\overrightarrow{0}}$ with $\mathrm{X}$ linked retardation demonstrated microcephaly and has since been shown to be negative for the fragile $\mathrm{X}^{6}$

Although the syndrome is extremely variable, the majority of patients with the fragile $X$ syndrome are only moderately or mildly retarded and are ambulant 3 . and capable of some speech and simple tasks. ${ }^{7}$ Our patients were severely to profoundly retarded, with $\frac{\text { 의 }}{3}$ seven having IQs from 30 to 35 and the remainder from not measurable to 30 . An over-representation by severe and profoundly retarded patients has been $\frac{7}{0}$ previously proffered as an explanation for a low. incidence of fragile $X$ among retarded patients with $N$ macro-orchidism. ${ }^{8}$

In summary, our small group of 17 male patients suggests that the absence of a positive family history and the presence of clinical findings, such as microcephaly, severe to profound retardation, and/or minor facial and digital anomalies unlike $\stackrel{\Phi}{+}$ those of the fragile $X$ syndrome, make the cytogenetic diagnosis of the syndrome unlikely. Although ${ }_{0}^{\circ}$ a degree of spasticity has been reported in the fragile $\overrightarrow{\mathbb{D}}$ $X$ syndrome, ${ }^{9}$ frank neurological signs are also $\frac{\rho}{\mathbb{D}}$

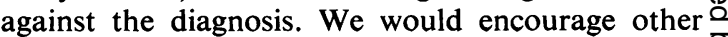


workers also to record the clinical details of their patients who have negative fragile $X$ studies. Criteria might then be developed to screen out those patients who do not require studies for the fragile $\mathrm{X}$.

Supported by the Mrs James A Richardson and Winnipeg Foundations.

\section{Alasdair G W Hunier, June MacDonald, AND JANE A Evans Division of Genetics, Children's Hospital of Eastern Ontario, 401 Smyth Road, Ottawa, Ontario, Canada K1H 8L1; and Division of Genetics, Winnipeg Children's Hospital, 695 Bannatyne Avenue, Winnipeg, Manitoba, Canada R3E OWI.}

\section{References}

1 Herbst DW, Miller JR. Non specific X-linked mental retardation. II. The frequency in British Columbia. Am J Med Genet 1980;7:461-9.
2 Hunter AGW, Evans JA, Thompson DR, Ramsay S. A study of institutionalized mentally retarded patients in Manitoba. I. Classification and preventability. Dev Med Child Neurol 1980;22:145-62.

3 Sutherland GR. Heritable fragile sites on human chromosomes. 1. Factors affecting expression in lymphocyte culture. Am J Hum Genet 1979;31:125-35.

4 Mattei MG, Mattei JR, Vidal I, Giraud F. Expression in lymphocyte and fibroblast culture of the fragile $X$ chromosome: a new technological approach. Hum Genet $1981 ; 59: 166-9$.

5 Jacobs PA, Glover TW, Mayer M, Fox P, Gerrard JW, Dunn HG, Herbst OS. X-linked mental retardation: a study of 7 families. Am J Med Genet 1980;7:471-89.

6 Fox P, Fox D, Gerrard JW. X-linked mental retardation: Renpenning revisited. Am J Hum Genet 1980;7:491-5.

7 Gustavson $\mathrm{KH}$, Holmgren $\mathrm{R}$, Blomquist $\mathrm{K}$, et al. Familial $X$-linked mental retardation and fragile $X$ chromosomes in two Swedish families. Clin Genet 1981; 19:101-10.

8 Nielsen KB, Duggve $\mathrm{H}$, Schou C. Macro-orchidism, mental retardation and the fragile X. $N$ Engl J Med 1981; 305:1348.

9 Jennings M, Hall JM, Hoehn H. Significance of phenotypic and chromosome abnormalities in X-linked mental retardation (Martin-Bell or Renpenning syndrome). Am J Med Genet 1980;7:417-32. 